\title{
A nitrogen-limited, glucose-repressed, continuous culture of Saccharomyces cerevisiae
}

\author{
Laurens N. Sierkstra, ${ }^{1}$ Eelko G. ter Schure, ${ }^{1}$ John M. A. Verbakel ${ }^{2}$ \\ and $C$. Theo Verrips ${ }^{1,2}$
}

Author for correspondence: Laurens N. Sierkstra. Tel: +3130 533349. Fax: + 3130513655.

1 Department of Molecular Cell Biology, University of Utrecht, Padualaan 8, $3584 \mathrm{CH}$ Utrecht, The Netherlands

2 Unilever Research Laboratorium Vlaardingen, Olivier van Noortlaan 120, 3133 AT Vlaardingen, The Netherlands
Glucose-repressed growth of Saccharomyces cerevisiae was analysed in a nitrogen-limited continuous culture at different dilution rates $(D)$. The glucose consumption of the yeast decreased from $3.4 \mathrm{~g} \mathrm{~g}^{-1} \mathrm{~h}^{-1}$ to $3.0 \mathrm{~g} \mathrm{~g}^{-1} \mathrm{~h}^{-1}$ when $D$ was decreased from $0.3 \mathrm{~h}^{-1}$ to $0.15 \mathrm{~h}^{1}$. No transcripts of the SUC2 and HXK1 genes, encoding, respectively, invertase and hexokinase isoenzyme 1 , could be detected. Because both genes are regulated by glucose repression at the transcriptional level, this confirmed that the culture was glucose repressed at every $D$. During the decrease in $D$, no change in the activities or mRNA levels of key enzymes in carbon metabolism was observed, except for alcohol dehydrogenases I and II and phosphoglucomutase. These enzymes increased in activity and/or mRNA level when $D$ was decreased, which was also observed in glucose- and galactose-limited continuous cultures. This demonstrates that the expression levels of alcohol dehydrogenases I and II, and also

phosphoglucomutase, are coupled to the growth rate of the organism. A comparison between the alcohol dehydrogenase II activity in glucose- and nitrogen-limited continuous cultures demonstrated that the growth rate contributes as much to repression of alcohol dehydrogenase II activity as does glucose. Both the glucose consumption and the activity of the glycolytic enzymes were relatively constant when $D$ was decreased and, as a consequence, the concentrations of intracellular metabolites remained constant. A slight decrease in the glucose 6-phosphate concentration was observed, which could be caused by the slight decrease in glucose consumption at low $D$ values. The 2-oxoglutarate and CAMP concentrations increased twofold when $D$ was decreased. The first probably reflects the increased $\mathrm{NH}_{4}$ consumption at high $D$ values, while the latter is caused by the high amount of extracellular CAMP compared with the amount of intracellular CAMP. The decrease in growth rate raised the amount of biomass, while nitrogen was limiting in all cases. Analysis of the biomass composition at the different $D$ values revealed that the amount of nitrogen per gram dry weight was constant, while the amounts of carbon, hydrogen and oxygen were higher at low $D$ values. In addition, higher concentrations of trehalose and glycogen were found at low $D$ values. This demonstrates that the glucose which is used at high $D$ values for the production of biomass is converted into storage carbohydrates, e.g. trehalose and glycogen, at low $D$ values. A nitrogen pulse did not result in a dramatic response of $S$. cerevisiae except for a rapid change in the free amino acid pool. Thus $S$. cerevisiae is not able rapidly to enhance growth upon a nitrogen pulse, which is in contrast with the response to a glucose pulse of a carbon-limited continuous culture of $S$. cerevisiae.

Keywords: Saccharomyces cerevisiae, glucose repression, nitrogen limitation, continuous culture, carbon metabolism 


\section{INTRODUCTION}

Glucose repression regulates the transcription of a number of genes in Saccharomyces cerevisiae dependent upon the availability of glucose or fructose as carbon sources. The presence of these carbon sources represses the transcription of, amongst others, genes whose products are involved in the utilization of carbon sources other than glucose or fructose (for a recent review, see Gancedo, 1992). The signal transduction pathway leading to transcriptional regulation of glucose-repressible genes has not yet been elucidated, but it has been shown that the mere presence of glucose is not sufficient to cause glucose repression of the SUC2 and HXK1 transcripts (Sierkstra et al., 1992a). This suggests that a threshold concentration of glucose or a glucose metabolite is involved in the generation of the initial signal. A number of proteins have been isolated which are involved in the repression of SUC2 transcription (Gancedo, 1992), and one of these, hexokinase II, was suggested to play a key role in the formation of the initial signal for glucose repression (Entian \& Frohlich, 1984; Ma et al., 1989; Rose et al., 1991). Recently the transcription factor MIG1 has been identified, which seems to specifically regulate glucoserepressible genes. MIG1 binding site consensus sequences have been identified in a number of glucose-repressible genes (Nehlin \& Ronne, 1990; Mercado et al., 1991; Sierkstra et al., 1992b). In addition, the repression of the $G A L$ genes encoding the enzymes of the Leloir pathway is also accomplished, in part, by MIG1-dependent regulation of GAL4 transcription (Nehlin et al., 1991; Griggs \& Johnston, 1991). ADR1, a transcription factor regulated by the cAMP-dependent protein kinase A (Cherry et al., 1989), has been implicated in the regulation of the transcription level of the glucose-repressible $A D H 2$ gene, encoding alcohol dehydrogenase II. Recent results, however, have suggested that $A D H 2$ is not solely regulated by glucose repression, and these data also showed that the expression level of this gene is dependent upon the growth rate or glycolytic flux of the yeast (Sierkstra et al., 1992a, 1993). Moreover, ADR1 seems to specifically regulate genes which are directly or indirectly involved in peroxisomal metabolism (Simon et al., 1991). So, although transcription factors have been identified as components of the glucose-repression pathway, the upstream regulation of these factors in the signal transduction cascade and the formation of the initial signal have not yet been elucidated.

Data concerning glucose repression are limited to shakeflask experiments performed under non-defined physiological conditions. Recently we have initiated a study to investigate glucose repression, and the signal transduction pathway involved, under defined physiological conditions in continuous cultures. A requirement for such a study is to first describe the exact physiological state of the yeast under glucose-derepressed and glucose-repressed growth. Therefore the levels of glycolytic intermediates, ATP and cAMP, and the activity and mRNA levels of key enzymes in carbon metabolism as well as physiological parameters, such as $\mathrm{CO}_{2}$ production and oxygen consumption, have been determined under glucose-derepressed conditions (Sierkstra et al., 1992a). In this study, glucose-repressed growth was analysed by cultivation of a commercial bakers' yeast under nitrogen limitation with an excess of glucose as carbon source.

\section{METHODS}

Strain and growth conditions. S. cerevisiae strain SU32 was grown at $30^{\circ} \mathrm{C}$ in a 2 litre fermenter connected to an Applikon ADI 1020 controller unit. $S$. cerevisiae was inoculated into the medium previously described (Sierkstra $t$ t al., 1992a) and, after overnight batch growth, a continuous feed with the same composition (resulting in a glucose-limited continuous culture) was connected. The dilution rate $(D)$ was increased and, at $D$ $0 \cdot 3 \mathrm{~h}^{-1}$, a nitrogen-limited feed was connected, which was identical to glucose-limited medium except that the amount of $\mathrm{NH}_{4} \mathrm{Cl}$ was decreased from $7.63 \mathrm{~g} \mathrm{l}^{-1}$ to $1.4 \mathrm{~g} \mathrm{l}^{-1}$ and the glucose concentration was $103 \mathrm{~g} \mathrm{l}^{-1}$ instead of $20 \mathrm{~g} \mathrm{l}^{-1}$. Subsequently the yeast was grown at $D 0.3 \mathrm{~h}^{-1}, 0.26 \mathrm{~h}^{-1}, 0.22 \mathrm{~h}^{-1}, 0.18 \mathrm{~h}^{-1}$ and $0 \cdot 15 \mathrm{~h}^{-1}$. During batch and glucose-limited growth, the $\mathrm{pH}$ was automatically controlled at $\mathrm{pH} 5$ by the addition of $5 \mathrm{M}$ $\mathrm{NH}_{4} \mathrm{OH}$, while during nitrogen-limited growth, the $\mathrm{pH}$ was controlled at $\mathrm{pH} 5$ with $5 \mathrm{M} \mathrm{KOH}$. The air flow rate was 2 litres $\mathrm{min}^{-1}$ and the oxygen tension was kept above $30 \%$ by regulation of the stirrer speed. $\mathrm{CO}_{2}$ production $\left[\mathrm{rCO}_{2} \mathrm{mmol} \mathrm{h}^{-1}\right.$ per gram dry wt $(\mathrm{g})]$, oxygen consumption $\left(\mathrm{qO}_{2}, \mathrm{mmol} \mathrm{g}^{-1} \mathrm{~h}^{-1}\right)$ and ethanol production were measured on line by connection of the headspace of the fermenter to a VG gas analysis mass spectrometer MM 8-80.

Preparation of samples. Preparation of cell-free extracts for enzyme assays, mRNA isolation for Northern blot analysis, extracts for metabolite determination and the determination of gram dry weight (abbreviated as g) per litre were performed as described previously (Sierkstra et al., 1992a). Sampling of culture liquid for the determination of extracellular metabolites (acetate, acetaldehyde, glycerol, pyruvate, ethanol and the residual glucose concentrations) was performed by quick filtration (within $10 \mathrm{~s}$ after sampling) of the culture liquid through a $0 \cdot 22 \mu \mathrm{m}$ pore-size Millipore filter.

Determination of metabolites, free amino acids and composition of dry weight. Extracellular metabolites were measured by means of HPLC analysis and/or enzymically on the Hoffmann La Roche Cobas Mira autoanalyser essentially as described by Bergmeyer (1974). Trehalose was measured according to Van Aelst (1991), with the modification that the glucose formed was measured by incubating the mixture with hexokinase, glucose-6-phosphate dehydrogenase and ATP. The amount of glycogen in the extracts was estimated with the $\alpha$ amylase kit (MA-KIT 30 Roche, no. 072062 3) of Hoffmann La Roche. Determination of the amount of nitrogen, carbon and hydrogen present in the dry yeast was performed on a Heraeus CHN RAPID analyser. Analysis of the oxygen content was performed according to Römer et al. (1972). All glycolytic metabolites were measured spectrophotometrically as described previously (Sierkstra et al., 1992a) on a Philips UV/VIS spectrophotometer series PU8700. Measurement of total cAMP was done with the Amersham cAMP kit according to the instruction manual. Analysis of free amino acids was performed on an ALPHA PLUS amino acid analyser, series 2 (Pharmacia/ LKB).

Enzyme assays. Enzyme activities were measured under $V_{\max }$ conditions essentially as described by Bergmeyer (1974). 

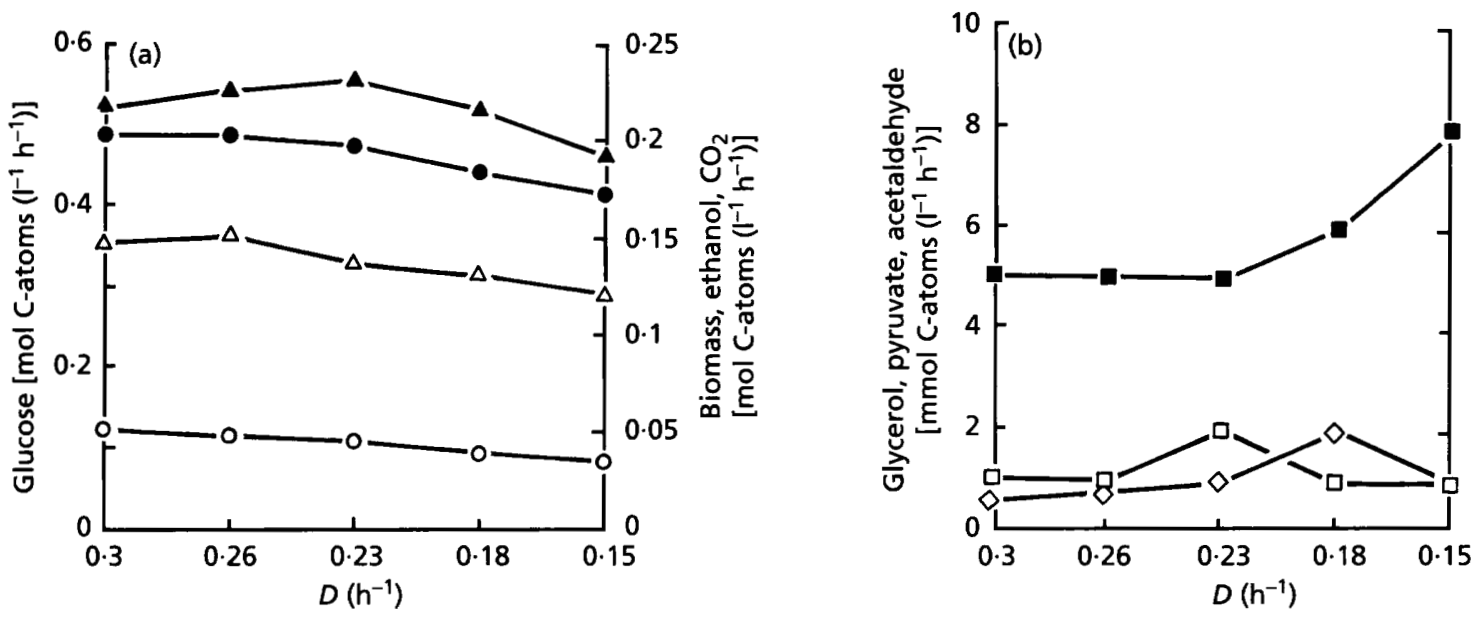

Fig. 1. (a) Consumption of glucose (O) and flux of carbon into biomass (O), ethanol $(\Delta)$ and $\mathrm{CO}_{2}(\triangle)$ (mol Catoms $\left.\mathrm{I}^{-1} \mathrm{~h}^{-1}\right) ;\left(\right.$ b) flux of carbon into acetaldehyde $(\diamond)$, glycerol $(\square)$ and pyruvate $(\square)$ (mmol C-atoms $\left.\mathrm{I}^{-1} \mathrm{~h}^{-1}\right)$. Results for the extracellular metabolites are the means of three independent samples. The standard error in this calculation is $\leqslant 10 \%$.

Reaction velocities were proportional to the amount of enzyme added. Activities are in $\mathrm{U}$ ( $\mathrm{mg}$ total cellular soluble protein $)^{\mathbf{1}}$, in which $1 \mathrm{U}$ is defined as the conversion of $1 \mu \mathrm{mol}$ substrate $\mathrm{min}^{-1}$ at $30^{\circ} \mathrm{C}$ at $\mathrm{pH} 7 \cdot 0$. All enzyme assays were performed on the Cobas Mira autoanalyser of Hoffmann La Roche. The protein content of the cell extracts was measured by the method of Bradford (1976) using the Bio-Rad reagent with BSA as a standard.

Labelling of oligonucleotides and Northern blot analysis. For the detection of specific mRNAs, labelled oligonucleotides described previously were used (Sierkstra et al., 1992a, b). Separation of $3 \mu \mathrm{g}$ total RNA, blotting of the gel, hybridization conditions and washing procedures have been previously described (Sierkstra et al., 1992a, b). In all experiments, actin or histone was used as an internal control for the amount of mRNA blotted. The amount of specific mRNA was measured on an LKB Ultroscan XL densitometer.

\section{RESULTS}

\section{Physiological parameters}

S. cerevisiae SU32 was grown under nitrogen limitation with $103 \mathrm{~g}$ glucose $\mathrm{l}^{-\mathbf{1}}$ in the feed at steady-state $D$ values of $0.3 \mathrm{~h}^{-1}, 0.26 \mathrm{~h}^{-1}, 0 \cdot 22 \mathrm{~h}^{-1}, 0 \cdot 18 \mathrm{~h}^{-1}$ and $0 \cdot 15 \mathrm{~h}^{-1}$. This succession of different $D$ values was employed to avoid flocculation, which was noticed at low $D$ values in initial experiments. Under nitrogen limitation, the cells were elongated, as observed by Gimeno et al. (1992), while the shape of the cells was normal under glucose limitation. At all $D$ values, the residual glucose and $\mathrm{NH}_{4}^{+}$concentrations were $>100 \mathrm{mmol} \mathrm{l}^{-1}$ and $<0.1 \mathrm{mmol} \mathrm{l}^{-1}$, respectively, while the oxygen consumption was constant at $3.8 \mathrm{mmol}$ $\mathrm{g}^{-1} \mathrm{~h}^{-1}$ (results not shown). The glucose consumption was constant at $3.4 \mathrm{~g} \mathrm{~g}^{-1} \mathrm{~h}^{-1}$ when $D$ was decreased from $0.3 \mathrm{~h}^{-1}$ to $0.26 \mathrm{~h}^{-1}$ and then gradually decreased to $3.0 \mathrm{~g} \mathrm{~g}^{-1} \mathrm{~h}^{-1}$ at $D 0.15 \mathrm{~h}^{-1}$. The flux of carbon into biomass should have decreased twofold when $D$ was decreased from $0.3 \mathrm{~h}^{-1}$ to $0.15 \mathrm{~h}^{-1}$; however a 1.4 -fold decrease was observed (Fig. 1a). The flux of carbon into ethanol and $\mathrm{CO}_{2}$ followed the pattern of glucose consumption, although a slight increase in the ethanol and $\mathrm{CO}_{2}$ flux could be observed when $D$ decreased from $0 \cdot 3 \mathrm{~h}^{-1}$ to $0.26 \mathrm{~h}^{-1}$ (Fig. 1a). The flux into glycerol and acetaldehyde increased (Fig. 1b), although the latter decreased again at $D 0.15 \mathrm{~h}^{-1}$. The carbon flux into pyruvate remained constant when $D$ was decreased, although a slight increase at $D 0 \cdot 23 \mathrm{~h}^{-1}$ was observed. No acetate could be detected in the medium $\left(\leqslant 0 \cdot 05 \mathrm{~g} \mathrm{l}^{-1}\right)$.

The composition of the biomass at different $D$ values was analysed and the amounts of carbon, hydrogen, oxygen and nitrogen were determined in the total amount of biomass (Table 1). A decrease in $D$ resulted in an increase in the amount of hydrogen, carbon and oxygen converted into biomass, whereas the amount of nitrogen remained constant.

\section{mRNA analysis}

The levels of the transcripts of the HXK2, PDC1, PDA1 and $P G I 1$ genes were constant with decreasing $D$ values. No SUC2 and no HXK1 mRNA could be detected (results not shown). The $A D H 1 / 2$ transcripts remained constant when $D$ was decreased from $0.3 \mathrm{~h}^{-1}$ to $0.23 \mathrm{~h}^{-1}$. A subsequent decrease in $D$ to $0 \cdot 15 \mathrm{~h}^{-1}$ resulted in a ninefold increase in $A D H 1 / A D H 2$ mRNA level (Fig. 2).

\section{Enzyme levels}

The activities of phosphoglucoisomerase, glucose-6phosphate dehydrogenase and pyruvate decarboxylase were constant at every $D$ at approximately $3 \cdot 2,0 \cdot 22$ and $0.5 \mathrm{U}$ (mg protein $)^{-1}$, respectively (Fig. $\left.3 \mathrm{a}\right)$. An increase in alcohol dehydrogenase I and II activity from, respectively, 0.012 and $0.025 \mathrm{U}$ (mg protein) $)^{-1}$ at $D 0.3 \mathrm{~h}^{-1}$ to 0.17 and $0.24 \mathrm{U}(\mathrm{mg} \text { protein) })^{-1}$ at $D 0.15 \mathrm{~h}^{-1}$ was observed. The phosphoglucomutase activity increased 
Table 1. Amounts of nitrogen, carbon, oxygen and hydrogen as a percentage of the total amount of biomass

Results are the means of two independently isolated samples, \pm the range.

\begin{tabular}{|lccccc|}
\hline $\boldsymbol{D}\left(\mathbf{h}^{-1}\right)$ & $\mathbf{N}(\%)$ & $\mathbf{C ~ ( \% )}$ & $\mathbf{O}(\mathbf{\%})$ & $\mathbf{H ~ ( \% )}$ & Biomass $\left(\mathbf{g ~}^{-\mathbf{1}}\right)$ \\
\hline 0.3 & $8.11 \pm 0.01$ & $43.68 \pm 0.06$ & $34.68 \pm 0.50$ & $6.24 \pm 0.06$ & $4.2 \pm 0.1$ \\
0.26 & $7.81 \pm 0.06$ & $43.78 \pm 0.05$ & $33.42 \pm 0.84$ & $6.17 \pm 0.08$ & $4.7 \pm 0.1$ \\
0.23 & $7.21 \pm 0.06$ & $43.56 \pm 0.12$ & $35.93 \pm 0.64$ & $6.01 \pm 0.28$ & $5.0 \pm 0.1$ \\
0.18 & $6.81 \pm 0.19$ & $43.77 \pm 0.30$ & $35.09 \pm 0.79$ & $6.39 \pm 0.03$ & $5.4 \pm 0.1$ \\
0.15 & $6.07 \pm 0.01$ & $43.60 \pm 0.07$ & $35.39 \pm 0.22$ & $6.24 \pm 0 \cdot 10$ & $5.9 \pm 0.3$ \\
\hline
\end{tabular}

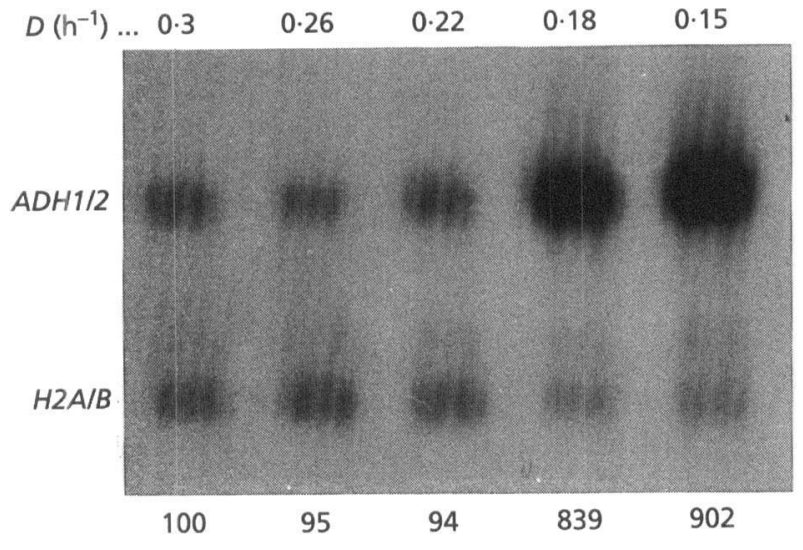

Fig. 2. Northern blot analysis of the $A D H 1 / A D H 2$ transcript at different $D$ values. The amount of specific mRNA is given beneath each lane as a percentage of the initial value at $D$ $0.3 \mathrm{~h}^{-1}$ and corrected for the internal standard $\mathrm{H} 2 \mathrm{~A} / \mathrm{H} 2 \mathrm{~B}$.

from $0.024 \mathrm{U}$ (mg protein) $)^{-1}$ at $D 0.3 \mathrm{~h}^{-1}$ to $0.112 \mathrm{U}$ (mg protein) $)^{-1}$ at $D 0.15 \mathrm{~h}^{-1}$ (Fig. $3 \mathrm{~b}$ ). The decrease from $D 0.3 \mathrm{~h}^{-1}$ to $D 0.15 \mathrm{~h}^{-1}$ resulted in a slight increase in the hexokinase activity from $0.9 \mathrm{U}(\mathrm{mg} \text { protein })^{-1}$ to $1.1 \mathrm{U}$ $(\mathrm{mg} \text { protein })^{-1}$.

\section{Metabolite levels}

The levels of glycolytic intermediate of the first part of glycolysis, ATP and cAMP were measured (Table 2). Glucose 6-phosphate decreased slightly during the decrease in $D$ in spite of the increase in hexokinase activity, while glucose 1-phosphate, fructose 1,6-diphosphate and fructose 6-phosphate remained constant. The level of ATP was constant at different $D$ values although it was slightly lower at $D 0 \cdot 15 \mathrm{~h}^{-1}$. Because of its importance as a metabolite at the branch point between carbon and nitrogen metabolism, 2-oxoglutarate was also measured. The concentrations of 2-oxoglutarate and cAMP were raised twofold when $D$ was decreased from $0.3 \mathrm{~h}^{-1}$ to $0 \cdot 15 \mathrm{~h}^{-1}$. At all $D$ values, the amount of extracellular cAMP was $>80 \%$ of the total amount of cAMP.

The concentration of the reserve/stress carbohydrates trehalose and glycogen increased from 0.0055 and $0.093 \mu \mathrm{mol} \mathrm{g}^{-1}$, respectively, at $D 0.3 \mathrm{~h}^{-1}$, to 0.36 and $1 \cdot 16 \mu \mathrm{mol} \mathrm{g}^{-1}$ at $D 0.15 \mathrm{~h}^{-1}$.
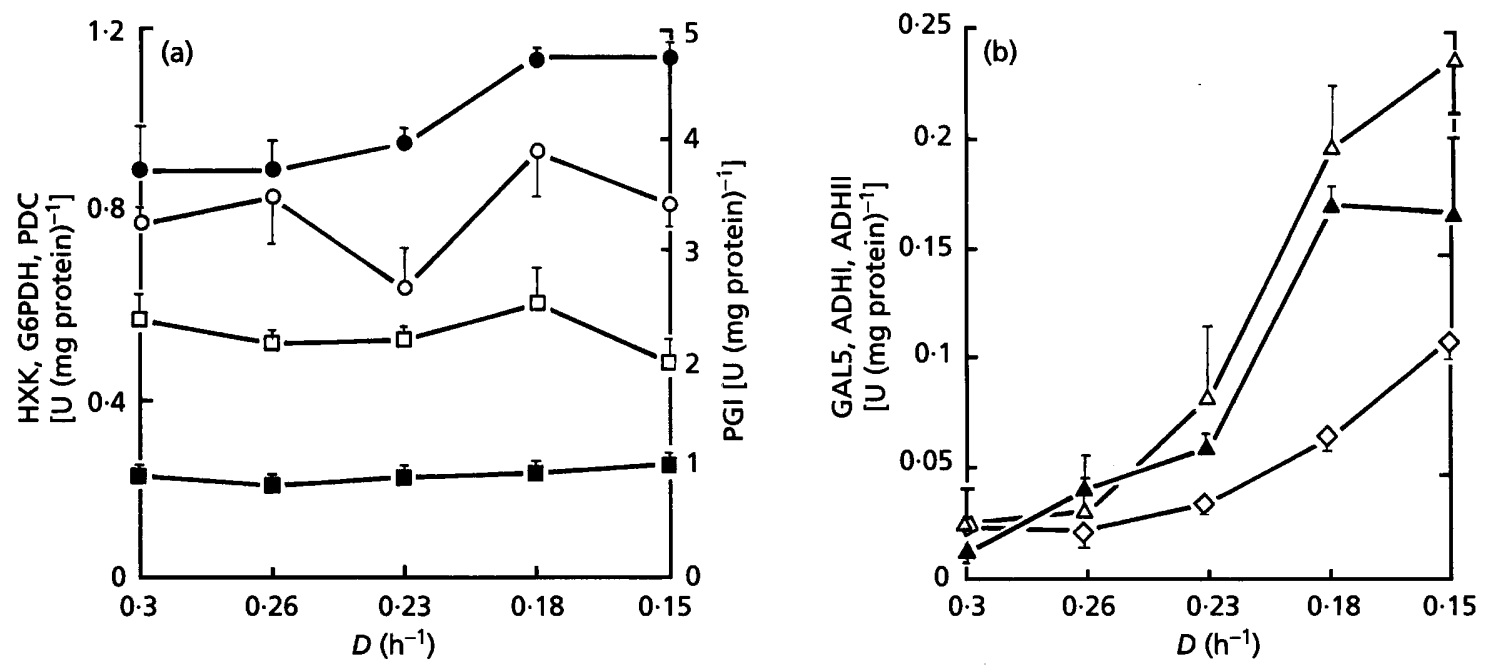

Fig. 3. Specific activities of the following enzymes as a function of $D:$ (a) HXK (hexokinase, O), PGI (phosphoglucoisomerase, O), PDC (pyruvate decarboxylase, $\square$ ) and G6PDH (glucose-6-phosphate dehydrogenase, $\square$ ); (b) GAL5 (phosphoglucomutase, $\diamond$ ), ADHI (alcohol dehydrogenase I, $\Delta$ ) and ADHII (alcohol dehydrogenase II, $\triangle$ ). Results shown are the means of three independently isolated samples assayed in duplicate. Bars indicate SE. 
Table 2. Concentrations of glucose 6-phosphate (g6p), fructose 6-phosphate (f6p), fructose 1,6-bisphosphate (f1,6bp),

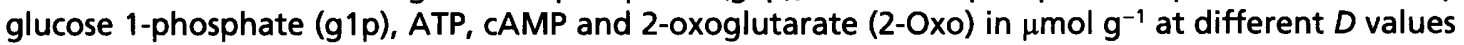

The concentrations are corrected for the increased amount of biomass produced at lower $D$ values. Results are the means of three independently isolated samples assayed in duplicate, $\pm \mathrm{SE}$.

\begin{tabular}{|lcccccrr|}
\hline $\boldsymbol{D}\left(\mathbf{h}^{-\mathbf{1}} \mathbf{)}\right.$ & g6p & f6p & f1,6bp & g1p & ATP & cAMP & 2-Oxo \\
\hline $0 \cdot 3$ & $2 \cdot 33 \pm 0 \cdot 36$ & $0 \cdot 33 \pm 0 \cdot 09$ & $20 \cdot 4 \pm 2 \cdot 1$ & $0 \cdot 25 \pm 0 \cdot 02$ & $5 \cdot 72 \pm 0 \cdot 43$ & $8 \cdot 0 \pm 0 \cdot 9$ & $50 \cdot 6 \pm 6 \cdot 0$ \\
$0 \cdot 26$ & $2 \cdot 42 \pm 0 \cdot 21$ & $0 \cdot 28 \pm 0 \cdot 18$ & $17 \cdot 0 \pm 2 \cdot 5$ & $0 \cdot 24 \pm 0 \cdot 12$ & $6 \cdot 28 \pm 0 \cdot 55$ & $8 \cdot 8 \pm 0 \cdot 6$ & $61 \cdot 8 \pm 7 \cdot 5$ \\
$0 \cdot 23$ & $2 \cdot 33 \pm 0 \cdot 30$ & $0 \cdot 36 \pm 0 \cdot 06$ & $18 \cdot 5 \pm 2 \cdot 1$ & $0 \cdot 31 \pm 0 \cdot 10$ & $5 \cdot 10 \pm 0 \cdot 25$ & $9 \cdot 4 \pm 0 \cdot 9$ & $78 \cdot 3 \pm 6 \cdot 9$ \\
$0 \cdot 18$ & $2 \cdot 05 \pm 0 \cdot 03$ & $0 \cdot 16 \pm 0 \cdot 01$ & $21 \cdot 5 \pm 1 \cdot 1$ & $0 \cdot 22 \pm 0 \cdot 12$ & $5 \cdot 32 \pm 0 \cdot 24$ & $13 \cdot 0 \pm 0 \cdot 7$ & $87 \cdot 3 \pm 6 \cdot 1$ \\
$0 \cdot 15$ & $1 \cdot 91 \pm 0 \cdot 32$ & $0 \cdot 33 \pm 0 \cdot 20$ & $21 \cdot 9 \pm 1 \cdot 8$ & $0 \cdot 24 \pm 0 \cdot 13$ & $4 \cdot 25 \pm 0 \cdot 56$ & $14 \cdot 2 \pm 1 \cdot 8$ & $102 \cdot 0 \pm 1 \cdot 6$ \\
\hline
\end{tabular}

\section{Nitrogen pulse}

A pulse of $0 \cdot 1 \mathrm{M} \mathrm{NH}_{4}^{+}$was given to the nitrogen-limited continuous culture at $D 0.3 \mathrm{~h}^{-1}$ in order to investigate the effect on carbon utilization and growth. An increase in the biomass could be seen 200 min after the nitrogen pulse. No significant change in the concentrations of intracellular metabolites, cAMP and ATP, or in the activities and mRNA levels of key enzymes in carbon metabolism, was observed after the pulse (results not shown). Only a slight decrease in the 2-oxoglutarate concentration could be detected $\left(46 \mu \mathrm{mol} \mathrm{g}^{-1}\right.$ at $t=0$ to $30 \mu \mathrm{mol} \mathrm{g}^{-1}$ at $t=$ 120). Analysis of the concentration of the free amino acids revealed that there were four patterns for the changes in amino acid concentration after a nitrogen pulse. No change in the concentrations of cysteine, leucine, methionine, isoleucine, valine and tyrosine could be observed. The concentrations of glutamate, arginine, proline, serine, lysine, glycine and phenylalanine increased $30 \mathrm{~min}$ after the pulse, while the concentrations of threonine and histidine increased $7.5 \mathrm{~min}$ after the addition of nitrogen. A direct increase in the concentrations of alanine, glutamine and aspartate was observed, although the concentration of aspartate decreased again $30 \mathrm{~min}$ after the pulse. Within $60 \mathrm{~min}$ after nitrogen addition, the total amino acid pool was increased from 300 to $700 \mu \mathrm{mol} \mathrm{g}^{-1}$ and thereafter remained constant (results not shown).

\section{DISCUSSION}

\section{Repression of respiration}

At all $D$ values the residual glucose concentration was $>100 \mathrm{mmoll}^{-1}$, while that of the limiting substrate, $\mathrm{NH}_{4}^{+}$, was $<0 \cdot 1 \mathrm{mmol}^{-1}$. No SUC2 or HXK1 mRNA could be detected. Both SUC2 and HXK1 are subject to glucose repression at the transcriptional level (Carlson, 1987; Sierkstra et al., 1992a), and this result demonstrates that the cells were glucose repressed at every $D$. The specific oxygen consumption was $3-3.8 \mathrm{mmol} \mathrm{g}^{-1} \mathrm{~h}^{-1}$ at every $D$. The maximum specific oxygen consumption observed under glucose-derepressed conditions for this strain is $7 \mathrm{mmol} \mathrm{g}^{-1} \mathrm{~h}^{-1}$ (Sierkstra et al., 1992a, 1993). Thus half of the maximum amount of oxygen is still consumed under glucose-repressed conditions. It has been reported that the enzymes of the citric acid cycle and oxidative phosphorylation are regulated by glucose repression (Holzer, 1976; Gancedo, 1992), and the difference in the specific oxygen consumption between glucose-derepresed and glucose-repressed cultures could reflect this repression of enzyme synthesis. However, when $D$ was increased in carbon-limited continuous cultures and ethanol production occurred, a decrease in the respiration to 3$3.5 \mathrm{mmol} \mathrm{g}^{-1} \mathrm{~h}^{-1}$ was observed (Sierkstra et al., 1992a, 1993). This decrease was not caused by glucose repression of respiration but by the altered metabolic state of the yeast at this $D$, which changed from completely respirative to respiro-fermentative; this could also explain the difference in respiration between glucose-derepressed and glucose-repressed cultures.

\section{Carbon fluxes}

The consumption of glucose was almost constant at 3-3.4 g glucose $\mathrm{g}^{-1} \mathrm{~h}^{-1}$ when the growth rate was decreased, which demonstrates that the maximal glucose consumption of yeasts is independent of the growth rate. The flux of carbon into biomass was only $1 \cdot 4$-fold higher at $D 0.3 \mathrm{~h}^{-1}$ as compared with $D 0 \cdot 15 \mathrm{~h}^{-1}$ instead of the theoretical twofold increase. This was caused by the fact that the biomass concentration in the fermenter was higher at $D 0.15 \mathrm{~h}^{-1}$. Analysis of the biomass composition showed that the amount of nitrogen was constant but that the amount of hydrogen, carbon and oxygen was higher at low $D$ values. Thus more carbon-, hydrogen- and oxygen-containing compounds are produced at lower $D$ values, which was confirmed by the measurement of trehalose and glycogen. This demonstrates that the glucose which is used at higher $D$ values for the formation of biomass is, at least in part, converted into reserve carbohydrates at low $D$ values. The flux of carbon into ethanol and $\mathrm{CO}_{2}$ decreased at low $D$ values, while the acetaldehyde and glycerol production increased. Increased glycerol production at low $D$ values could have the same function as trehalose and glycogen production. The decreased ethanol flux is in contrast to the higher alcohol dehydrogenase I activity at low $D$ values. This result suggests that the conversion of acetaldehyde into ethanol in S. cerevisiae is, under these conditions, regulated by the availability of co-factors such as NADH and NAD, instead of the amount of enzyme. No acetate could be 
detected (detection limit $<0.05 \mathrm{~g} \mathrm{l}^{-1}$ ). The strain is capable of acetate production (Sierkstra et al., 1992a), but in this case either the acetyl-CoA synthetase bypass (Postma et al., 1989) is not used or the affinity of acetylCoA synthetase for acetate is greatly enhanced under these conditions, resulting in undetectable residual acetate levels. The decrease in $D$ left the concentrations of the glycolytic intermediates constant, which is in accordance with the virtually constant uptake of glucose and constant glycolytic enzyme levels. Only a slight decrease in glucose 6-phosphate concentration was observed, which coincided with the slight decrease in glucose consumption. In contrast, the concentrations of total cAMP (intra- and extracellular) and 2-oxoglutarate both increased twofold when the dilution was decreased. Because cAMP is mostly found extracellularly, the twofold decrease in $D$ will result in a twofold increase in the total cAMP concentration. The lower intracellular 2-oxoglutarate concentration at high $D$ values is probably caused by the increased formation of glutamine because more $\mathrm{NH}_{4}^{+}$is available per hour at higher $D$ values.

\section{Expression of key enzymes in carbon metabolism}

The change in $D$ under glucose-repressed conditions had no effect on the activities and mRNA levels of key enzymes in carbon metabolism, apart from phosphoglucomutase and alcohol dehydrogenases I and II, which increased with decreasing dilution rates. This was also observed in glucose- and galactose-limited continuous cultures (Sierkstra et al., 1992a, 1993), which demonstrates that alcohol dehydrogenase II is not exclusively regulated by glucose but that the expression level of this gene is coupled to the growth rate of the organism. In addition, the growth rate significantly contributes to the regulation of alcohol dehydrogenase I and phosphoglucomutase.

\section{Comparison of the expression levels of key enzymes during glucose-repressed versus glucose-derepressed growth}

Activity measurements in both glucose- (Sierkstra et al., 1992a) and nitrogen-limited continuous cultures showed that phosphoglucoisomerase and glucose-6-phosphate dehydrogenase have identical activities under both growth conditions. Pyruvate decarboxylase activity is induced two- to threefold, while the total hexose phosphorylating capacity is twofold lower under glucose repression, probably reflecting the absence of the HXK1 transcript. Phosphoglucomutase activity is $10-20$-fold lower under repressed growth conditions, indicating that, in contrast to other reports (Johnston, 1987), this gene is also regulated by carbon source. Alcohol dehydrogenase II activity was reduced tenfold under glucose-repressed conditions as compared with glucose-derepressed conditions (at $D 0.3 \mathrm{~h}^{-1}$ ), while a tenfold increase in activity was also observed when $D$ was decreased from $0.3 \mathrm{~h}^{-1}$ to $0.15 \mathrm{~h}^{-1}$. This demonstrates that the contribution of the growth rate to the regulation of alcohol dehydrogenase II levels is at least as important as the regulation of alcohol dehydrogenase II by glucose repression.

\section{Nitrogen pulse}

A nitrogen pulse had limited effects upon the carbon metabolism and growth rate of $S$. cerevisiae. No direct change in $\mathrm{CO}_{2}$ production, oxygen consumption and biomass could be detected. Moreover, no effect of the nitrogen pulse on the concentrations of intracellular metabolites and on the expression of the above mentioned genes (translational or transcriptional level) could be detected. Only the intracellular amino acid pool changed: from low to high amino acid levels. After glucose pulses to carbon-limited continuous cultures, increased cAMP production was observed and, furthermore, the mRNA level of glucose-regulated genes was altered (Sierkstra $e t$ al., 1992b). The measurements performed in this study did not reveal a nitrogen-induced signal transduction cascade involved in the regulation of carbon utilization in $S$. cerevisiae. Additional experiments are currently being performed to further investigate nitrogen-specific signal transduction pathways in yeast with emphasis on inositol 1,4,5-phosphate metabolism (Schomerus \& Küntzel, 1992), GCN4-mediated transcription (Hinnebusch, 1988) and NCR-regulated transcription (e.g. Cooper et al., 1992).

\section{REFERENCES}

Bergmeyer, H. U. (1974). Methods of Enzymatic Analysis. Weinheim: Verlag Chemie.

Bradford, M. M. (1976). A rapid and sensitive method for the quantitation of microgram quantities of protein utilizing the principle of protein-dye binding. Anal Biochem 72, 248-254.

Carlson, M. (1987). Regulation of sugar utilization in Saccharomyces species. $J$ Bacteriol 169, 4873-4877.

Cherry, J. R., Johnson, T. R., Dollard, C., Shuster, J. R. \& Denis, C. L. (1989). cAMP dependent protein kinase phosphorylates and inactivates the yeast transcriptional activator ADR1. Cell 56, 409-419.

Cooper, T. G., Kovari, L., Sumrada, R. A., Park, H. D., Luche, R. M. \& Kovari, I. (1992). Nitrogen catabolite repression of arginase ( $C A R 1)$ expression in Saccharomyces cerevisiae is derived from regulated inducer exclusion. $J$ Bacteriol 174, 48-55.

Entian, K. D. \& Frohlich, K. U. (1984). Saccharomyces cerevisiae mutants provide evidence of hexokinase PII as a bifunctional enzyme with catalytic and regulatory domains for triggering catabolite repression. J Bacteriol 158, 29-35.

Gancedo, J. M. (1992). Carbon catabolite repression in yeast. Eur J Biochem 206, 297-313.

Gimeno, C. J., Ljungdahl, P. O., Styles, C. A. \& Fink, G. R. (1992). Unipolar cell divisions in the yeast Saccharomyces cerevisiae lead to filamentous growth: regulation by starvation and $R A S$. Cell 68, 1077-1090.

Griggs, D. W. \& Johnston, M. (1991). Regulated expression of the $G A L 4$ activator gene in yeast provides a sensitive switch for glucose repression. Proc Nat Acad Sci US A 88, 8597-8601.

Hinnebusch, A. G. (1988). Mechanism of gene regulation in the general control of amino acid biosynthesis in Saccharomyces cerevisiae. Microbiol Rev 52, 248-273.

Holzer, H. (1976). Catabolite inactivation in yeast. Trends Biochem $S_{c i}$ 1, 178-181. 
Johnston, $M$. (1987). A model fungal gene regulatory mechanism: the GAL genes of Saccharomyces cerevisiae. Microbiol Rev 51, 458-476.

Ma, H., Bloom, L. M., Walsh, C. T. \& Botstein, D. (1989). The residual enzymatic phosphorylation activity of hexokinase II mutants is correlated with glucose repression in Saccharomyces cerevisiae. Mol Cell Biol 9, 5643-5649.

Mercado, J. J., Vincent, O. \& Gancedo, J. M. (1991). Regions in the promoter of the yeast FBP1 gene implicated in catabolite repression may bind the product of the regulatory gene MIG1. FEBS Lett 291, 97-100.

Nehlin, J. O. \& Ronne, H. (1990). Yeast MIG1 repressor is related to the mammalian early growth response and Wilms' tumour finger proteins. EMBO J 9, 2891-2898.

Nehlin, J. O., Carlberg, M. \& Ronne, H. (1991). Control of yeast $G A L$ genes by MIG1 repressor; a transcriptional cascade in the glucose response. EMBO J 10, 3373-3378.

Postma, E., Verduyn, C., Scheffers, W. A. \& Van Dijken, J. P. (1989). Enzymic analysis of the Crabtree effect in glucose-limited chemostat cultures of Saccharomyces cerevisiae. Appl Environ Microbiol $55,468-477$.

Römer, F. G., van Osch, G. W., Buis, W. J. \& Griepink, B. (1972). Automation of carbon determinations. II. Automatic determination of $\mathrm{mg}$ amounts of carbon dioxide and its application to oxygen determination in organic substances. Mikrochim Acta, 674-679.

Rose, M., Albig, W. \& Entian, K. D. (1991). Glucose repression in
Saccbaromyces cerevisiae is directly associated with hexose phosphorylation by hexokinases PI and PII. Eur J Biochem 199, 511-518.

Schomerus, C. \& Kuntzel, H. (1992). CDC25-dependent induction of inositol 1,4,5-triphosphate and diacylglycerol in Saccharomyces cerevisiae by nitrogen. FEBS Lett 307, 249-252.

Sierkstra, L. N., Verbakel, J. M. A. \& Verrips, C. T. (1992a). Analysis of transcription and translation of glycolytic enzymes in glucoselimited continuous cultures of Saccharomyces cerevisiae. J Gen Microbiol 138, 2559-2566.

Sierkstra, L. N., Nouwen, N. P., Verbakel, J. M. A. \& Verrips, C. T. (1992b). Analysis of glucose repression by pulsing glucose to a galactose limited continuous culture of Saccharomyces cerevisiae. Yeast 8, 1077-1087.

Sierkstra, L. N., Nouwen, N. P., Verbakel, J. M. A. \& Verrips, C. T. (1993). Regulation of glycolytic enzymes and the Crabtree effect in galactose limited continuous cultures of Saccharomyces cerevisiae. Yeast (in press).

Simon, M., Adam, G., Rapatz, W., Spevak, W. \& Ruis, H. (1991). The Saccharomyces cerevisiae $A D R 1$ gene is a positive regulator of transcription of genes encoding peroxisomal proteins. Mol Cell Biol 11, 699-704.

Van Aelst, A. A. (1991). Glucose control of the $\mathrm{R} A S$-adenylate cyclase patbway in the yeast $S$. cerevisiae. $\mathrm{PhD}$ thesis, Katholieke Universiteit Leuven, Belgium.

Received 24 June 1993; accepted 2 December 1993. 